Research Article

\title{
Experimental and Numerical Simulation Studies of RC Beams under the Actions of Equal Energy Impact Loads
}

\author{
Xiwu Zhou $\mathbb{D}^{\mathbb{B}}$, Xiangyu Wang $\mathbb{D}^{\mathbb{D}}$, Runcheng Zhang, and Wen Zhang \\ School of Transportation and Civil Engineering \& Architecture, Foshan University, Foshan, China \\ Correspondence should be addressed to Xiangyu Wang; w2013754112@163.com
}

Received 12 September 2020; Revised 24 November 2020; Accepted 12 December 2020; Published 28 December 2020

Academic Editor: Xinyu Ye

Copyright $\odot 2020$ Xiwu Zhou et al. This is an open access article distributed under the Creative Commons Attribution License, which permits unrestricted use, distribution, and reproduction in any medium, provided the original work is properly cited.

In this study, two groups of RC beams were subjected to low-speed drop weight impact test by using the domestic advanced ultrahigh heavy-duty drop weight impact testing machine system. The main aspects studied are the influence of the combination of different impact velocity and mass on the dynamic response and local and global damage change of RC beam under the same impact energy. Next, the numerical model considering material strain rate is established using ABAQUS finite element software to verify and expand the experimental results. The results show the following: (1) under the condition of equal energy, the peak value of impact force measured in this experiment increases with the increase of impact velocity, yet the mid span displacement and rebar strain first increase and then decrease. In addition, when the impact velocity is $2.25 \mathrm{~m} / \mathrm{s}$ and the impact mass is $400 \mathrm{~kg}$, the beam has the most serious damage; (2) compared with the mass, the impact velocity has more obvious effects on the peak value of cumulative impact force, mid span displacement, and rebar strain; (3) with the decrease of the impact velocity (the increase of the mass), the local damage of the beam is gradually weakened and the overall damage is gradually exacerbated. The failure mode of the beam is transformed from local punching shear failure to overall static failure type.

\section{Introduction}

In some special scenarios, RC beams may be impacted by heavy objects during service, such as containers falling from port terminals and stones rolling down mountains [1]. In order to avoid catastrophic structural failures, impact loads should be additionally considered in the structural designs of $\mathrm{RC}$ beams in potential special scenarios cases.

Under the conditions of impact loads, material may be subjected to the strain rate effects, and the dynamic constitutive will be quite different from the static constitutive. The strain rate effects will change the strength and stiffness levels of the reinforcements and concrete material, resulting in the bearing capacity of the beams becoming improved when compared with that under static load conditions [2]. At the same time, the stress wave effects will also change the stress distribution range of the beams after impact occurs, and the stress of the beams will transition from midspan to support with the propagation of the stress waves [3]. The shear effects will mainly affect the midspan. Therefore, the higher the impact velocity is, the more obvious the shear effects will be, and the more serious the local damages will be. The influencing effects on the overall failure will tend to first increase and then decrease [4]. It has been found that the inertial force effects are the key factors which will affect the overall failure of the RC beams, and the size and range of the inertial force distribution are the main reasons for the changes in the overall failure modes of the beams [5]. These four types of effects jointly impact the mechanical behaviors of the beams under impact load conditions and are quite different from the impacts observed under static load conditions. The influences of impact loads on the impact resistance behaviors of beams have always been a hot topic in this field of research. Li [6] used falling weight impact tests and found that the higher the impact velocity is, the more quickly the stiffness of the damaged beams would decrease. However, it was observed that with enhancements of the strain rate effect, the impact resistance bearing capacity of the beams had increased. Zhou et al. [7] also carried out falling weight impact tests of stainless-steel concrete beams. 
The results revealed that the stainless-steel concrete beams still maintained better dynamic mechanical properties under high impact velocity conditions and that the impact force, displacements, and strain levels had noticeably increased with the increases of impact velocity. However, during the impact process, when the impact force reaches the peak value, the specimen begins to displace and the specimen does not appear to undergo obvious damage, except for the local area. The impact force is transformed into the corresponding inertial force and supporting reaction force. Therefore, the impact resistance of the beam is not accurately reflected by the impact force. In another related study, Gholipour et al. [8] used the finite element software LS-DYNA to simulate the influence of a close-in explosion loading, with variedrate impact loadings on the residual capacities and damage behavior of reinforced concrete beams. They proposed the residual flexural and shear capacities model of beams based on damage index and investigated different loading phases so as to assess the sensitivities of the RC beams to the impact loading rate when subjected to different combination modes. Through experimental testing, Fang et al. [9] found that the impact durations were reduced with the increases in impact velocity, and the impact durations were also increased with the increases in impact mass. Kishi et al. [10] found that the bearing reaction force increased with increases in impact velocity when the impact velocity was small. However, when the velocity reached a certain value, the bearing reaction force had not further increased. These findings indicated that the bearing reaction force cannot precisely express the impact bearing capacity of the beam. Ozbolt and Sharma [11] adopted numerical simulations to determine that, with increases in impact velocity, the failure modes of the examined beams had changed from bending failures to shear failures. Dey et al. [12] observed that the peak values of the impact force and the stiffness of fiber reinforced concrete beams gradually decreased under the same cumulative impact velocity conditions. Zhou et al. [13] found that the peak values of the cumulative impact force increased with the increases of impact velocity. In addition, the mechanical behavior of the beam changes with the type of impact load. The above experiments mainly covered the influence of the loading method on the dynamic response and mechanical behavior of the beam under different energy impacts. However, there are relatively few experimental studies addressing the falling weight impact of beams, under the same collision energy, with different loading methods. In particular, there remains a lack of research regarding the development and change of beam damage during single and cumulative impacts with equal energy.

At the same time, the local damages to the beamhammer contact areas in the midspan were obvious under the impact loads, and the local damages had affected the overall damage to the beams. Zhang et al. [14] studied the nonlinear dynamic response and failure behavior of simply supported beam under the action of medium velocity impact load and explosion load and found that the lower part of the middle span of the beam was first spalled due to local punching failure. Dou et al. [15] carried out the falling weight impact tests by using high-strength concrete beams.
The results revealed that increases in the concrete strength had little effect on the overall dynamic responses of the beams, yet could potentially reduce the local damage degrees of the beams. In the falling weight research conducted by Jin et al. [16], it was found that the higher the stirrup reinforcement ratios were, the smaller the local damages would be, and the beams were more prone to bending failures. The influences of impact velocities on local and overall damage degrees were investigated by Zhao and Yi [17]. It was found that the higher the impact velocity was, the smaller the proportion of kinetic energy from the falling hammers being converted into overall deformation energy consumption would be. In addition, more energy was used for the local damages in the beam-hammer contact areas. Due to the complexity and short durations of the local beam damages [18], the influences of the changes in impact velocity and mass on the scope, degree, and type of local damage required further investigation. In particular, the influencing effects of the local damages on the overall damage degrees remained unclear. In addition, combinations of experimental research techniques and numerical simulations were believed to have the potential to better illustrate the mechanical behaviors and damage changes of beams under impact load conditions. At the present time, equivalent degrees of freedom methods and simple elastoplastic impact analysis methods are the main finite element analysis methods used in the study of beams subjected to impact loads $[19,20]$. For example, Jin et al. [21] examined the impact resistance of steel fiberreinforced concrete beams by combining experimental methods and numerical simulations. It has been found that the addition of steel fibers to concrete beams can reduce the beam deformation and enhance the shear resistance of the beams. Zhang et al. [22] studied the mechanical behaviors of the beam under falling weight impact loads and high temperature dead loads through experimental processes and finite element methods.

In this investigation, a domestic advanced ultrahigh heavy-type falling weight impact testing machine system was utilized to carry out impact tests on two groups of reinforced concrete beams with bending failure and shear failure, respectively, under static load conditions. Then, combined with a finite element model, the influencing effects of drop hammers with different masses and velocity combinations on the mechanical behaviors and damage changes of reinforced concrete beams under the same energy were studied. The results obtained in this study may potentially provide important technical support for future impact resistance beam designs, as well as the evaluations of the impact resistance of existing structures.

\section{Design of the Experimental Test}

2.1. Specimen Design and Testing Method. In this study's experimental testing processes, two groups of reinforced concrete rectangular beams with different reinforcement ratios were designed. The specimens were $2.0 \mathrm{~m}$ in length with net spans of $1.8 \mathrm{~m}$, section sizes of $b \times h=150 \mathrm{~mm} \times 300 \mathrm{~mm}$. and reinforcement cover thicknesses of $25 \mathrm{~mm}$. The longitudinal reinforcements were 
HRB400 reinforcements with yield strength of $420 \mathrm{MPa}$, and the stirrups were HRB300 reinforcement with yield strength of $302 \mathrm{MPa}$. The concrete strength grade was $\mathrm{C} 40$, and the strength measured by the test was $43.7 \mathrm{MPa}$. The specimens were constructed by adopting formwork pouring and manual vibration methods and then cured at room temperature for 28 days. A section of the Group A beam is shown in Figure 1.

The longitudinal reinforcement ratio of Group A was relatively small, the bending-to-shear capacity ratio of the beams was $88.36 \mathrm{KN} / 140.37 \mathrm{KN}$, and the main failure mode was bending failure under static loads. The longitudinal reinforcement ratio of Group $B$ was higher than that of Group A, the bending-to-shear capacity ratio of the beams was $143.26 \mathrm{KN} / 140.37 \mathrm{KN}$, and the main failure was shear failure under static loads. The design of this study's experimental tests is shown in Table 1. Three identical specimen beams from each group were impacted with the same energy. However, the weights and speeds of the falling weights were different. Cumulative impact tests were carried out on the L16-1 and L16-3 beams, and single impact tests were conducted on the remaining beams. The impact velocity values and the impact force of the falling weights, midspan displacements, reinforcement strain of the measuring points, and damage development of the specimens during the impact processes were collected and recorded. Then, by comparing and analyzing the two groups of beams with different mechanical properties, the impact resistance responses of the RC beams under equal energy impact loads could be accurately evaluated.

The calculation equation of the design parameters in Table 1 is as follows:

$$
\begin{aligned}
E_{I} & =\frac{m v^{2}}{2}, \\
v & =\sqrt{2(g-a) \times h}, \\
a & =\frac{F}{m},
\end{aligned}
$$

where $E_{I}$ is the impact energy, $m$ is the weight of the drop hammer, $v$ is the theoretical impact velocity, $g$ is the acceleration due to gravity, $a$ is the acceleration caused by friction, $h$ is the measured height of the drop hammer, and $F$ is the measured track friction force.

2.2. Testing Device and Data Acquisition Process. This study's tests were carried out in the ultrahigh falling weight impact laboratory of Foshan University, and the device used for the testing processes is shown in Figure 2. As can be seen in the figure, the beam was placed on a fixed hinge bearing and the impact point of the hammer head was in the midspan area. A force sensor was embedded in the hammer head in order to measure the time history of the impact force. The hammer was a cylindrical flat hammer head with a diameter of $200 \mathrm{~mm}$. The falling hammer had gone into a free fall state approximately along the vertical guide rail and impacted the beam at its midspan position. The mass of the falling weight could be adjusted by adding or reducing counterweight plates. Considering the friction between the falling hammer and the track, the instantaneous speed of the falling weight was measured by a laser speed measuring device. When the hammer head contacted the beam, the instantaneous velocity changed and the data acquisition was triggered. The midspan deflection under the impact load was measured by a pull lever-type displacement meter arranged in the midspan of the beam. In addition, a resistance strain gauge was used to measure the strain of stressed reinforcements, and the distribution of the measuring points is detailed in Figure 1. Among the measuring points, the No. 1 and No. 4 measuring points were located at the midspan position of the beam. In order to measure the maximum strain of the load-bearing reinforcements, the No. 2 and No. 3 measuring points were located at the symmetrical position of one-quarter of the beam, and the strain under impact was relatively small. These findings provided important references for the subsequent comparisons of the reinforcement strain level of different beams. Also, a high-speed camera was adopted to record the impact test processes.

\section{Analysis of the Impact Test Results}

In this study, the test results of the Group A and Group B beams with different reinforcement ratios under equal energy impact loads were processed. The peak values of the impact force and rebound mechanism, peak displacements, and residual displacements, as well as the peak values of the reinforcement strain, were further analyzed. The cumulative impact tests of the two beams in Group A were carried out three times, and the impact test results are detailed in Table 2.

In Table 2, L16-1 represents that the beam is impacted by the first type of load, and L16-1-1 represents the first impact of the beam under the first type of load. The reinforcement strain is expressed by microstrain: $1 \xi=10^{6} \mu \xi$.

3.1. Analysis of Primary Impact Data. The time-history curves of the impact force are shown in Figure 3. The impact force level when the falling hammer collided with the beam was measured by a built-in force sensor in the hammer head, and the impact force time-history curves of the three beams in each group were merged into one chart. In this study's experiments, at the moment when the drop hammer collided with the beam, the impact force was observed to rapidly reach a peak value and then decreased rapidly, forming a wave peak. Then, the impact force vibrated and tended toward the horizontal. Due to the relatively large contact stiffness of the beam-hammer in the test, the signal transmitted by the force sensor will have overshoot phenomenon, so the impact force of some beams will appear negative values. By comparing the two figures, it could be seen that under the same energy impact load, when the impact velocity increased from $1.84 \mathrm{~m} / \mathrm{s}$ to $3.18 \mathrm{~m} / \mathrm{s}$, the peak impact force of the Group A beam increased by $70 \%$ and that of Group B increased by $61 \%$. Furthermore, the peak impact force increased by $4 \%$ from beam L16-1 to beam L20-1, and 


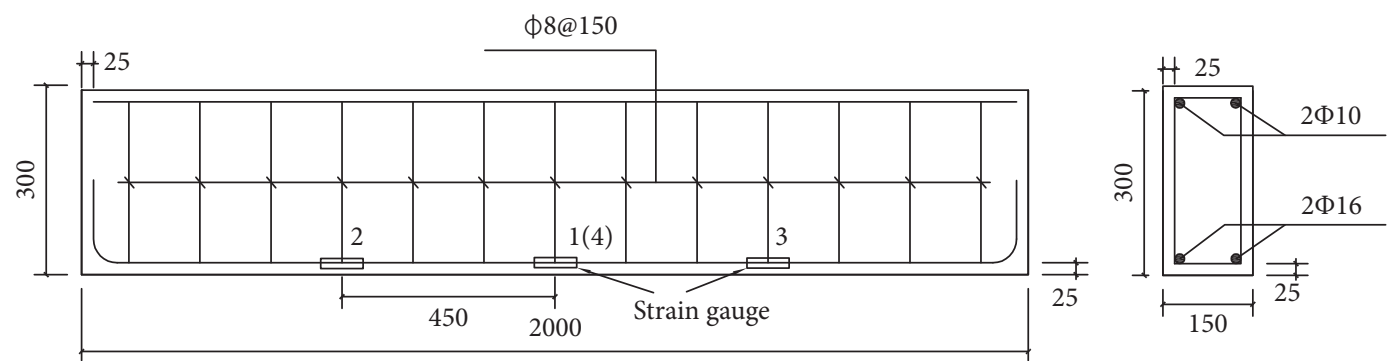

Figure 1: Reinforcement diagram of the Group A beam (mm).

TABle 1: Experimental test design.

\begin{tabular}{|c|c|c|c|c|c|c|c|c|c|}
\hline \multirow[b]{2}{*}{ Group } & \multirow{2}{*}{$\begin{array}{l}\text { Specimen } \\
\text { no. }\end{array}$} & \multirow{2}{*}{$\begin{array}{l}\text { Bottom } \\
\text { reinforcement }\end{array}$} & \multirow{2}{*}{$\begin{array}{l}\text { Erection } \\
\text { bar }\end{array}$} & \multirow[b]{2}{*}{ Stirrup } & \multirow{2}{*}{$\begin{array}{c}\text { Primary } \\
\text { impact } \\
\text { energy }(\mathrm{J})\end{array}$} & \multirow{2}{*}{$\begin{array}{c}\text { Falling } \\
\text { weight } \\
\text { (kg) }\end{array}$} & \multicolumn{3}{|c|}{ Falling height (theoretical impact velocity) } \\
\hline & & & & & & & First & Second & Third \\
\hline \multirow{4}{*}{ A } & L16-1 & & \multirow{6}{*}{$2 \Phi 10$} & & 1011.24 & 200 & $1.02 \mathrm{~m}(3.18 \mathrm{~m} / \mathrm{s})$ & $2.04 \mathrm{~m}(5.06 \mathrm{~m} / \mathrm{s})$ & $3.06 \mathrm{~m}(6.39 \mathrm{~m} / \mathrm{s})$ \\
\hline & L16-2 & $2 \Phi 16$ & & & 1012.50 & 400 & $0.50 \mathrm{~m}(2.25 \mathrm{~m} / \mathrm{s})$ & & - \\
\hline & L16-3 & & & $\phi 8 @$ & 1015.68 & 600 & $0.33 \mathrm{~m}(1.84 \mathrm{~m} / \mathrm{s})$ & $0.66 \mathrm{~m}(2.92 \mathrm{~m} / \mathrm{s})$ & $0.99 \mathrm{~m}(3.69 \mathrm{~m} / \mathrm{s})$ \\
\hline & L20-1 & & & 150 & 1011.24 & 200 & $1.02 \mathrm{~m}(3.18 \mathrm{~m} / \mathrm{s})$ & & \\
\hline \multirow[t]{2}{*}{ B } & L20-2 & $2 \Phi 20$ & & & 1012.50 & 400 & $0.50 \mathrm{~m}(2.25 \mathrm{~m} / \mathrm{s})$ & & - \\
\hline & L20-3 & & & & 1015.68 & 600 & $0.33 \mathrm{~m}(1.84 \mathrm{~m} / \mathrm{s})$ & & \\
\hline
\end{tabular}

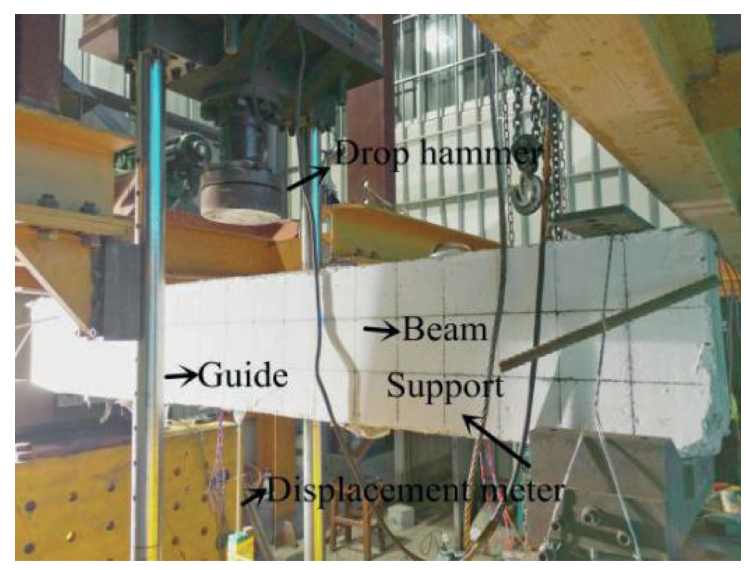

(a)

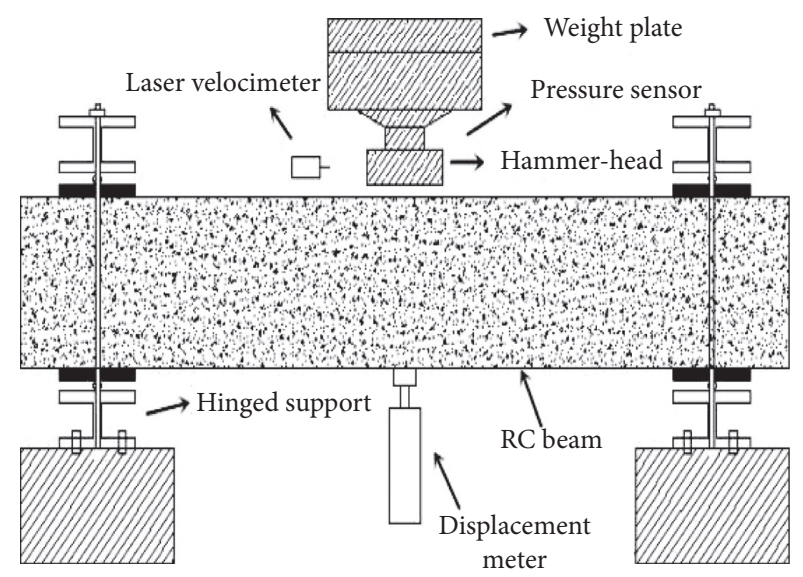

(b)

FIGURE 2: Falling weight impact test device (mm).

the peak impact force of the four remaining beams increased at different degrees with the increases in the reinforcement ratios. In addition, during the oscillation processes of the impact force curves after the first peak value was attained, only the impact force time history curves of the L16-1 and L20-1 beams with higher speed appeared to display secondary peak values. The secondary peak values of the impact force of the L20-1 reinforced beam with a larger reinforcement ratio were higher than those of the L16-1 reinforced beam. The main reason for this phenomenon was that, in the existing impact force formula [23], the power of the mass was secondary to the power of the velocity. Therefore, the impact velocity had greater impacts on the trends of the impact force time-history curves than the mass. In addition, the reinforcement ratio of the L20 beam was larger, so the overall stiffness of beam was greater. The stiffness affects the magnitude and frequency of subsequent peaks of the beam impact force time-history curve. As a result, the increases in velocity and stiffness were the main reasons for the subsequent peak values of the beams under the action of equal energy impact loads.

The displacement time-history curve of the beam under impact load is shown in Figure 4. After the drop hammer had collided with the beam, the midspan displacements were observed to increase with the downward movement of the beam and then decreased after reaching a peak value to form 
TABLE 2: Test results.

\begin{tabular}{|c|c|c|c|c|c|}
\hline Group & $\begin{array}{c}\text { Specimen } \\
\text { no. }\end{array}$ & $\begin{array}{c}\text { Impact velocity (mass) } \\
\mathrm{m} / \mathrm{s}(\mathrm{kg})\end{array}$ & $\begin{array}{c}\text { Peak value of the impact } \\
\text { force }(\mathrm{N})\end{array}$ & $\begin{array}{l}\text { Peak value of the displacements } \\
\qquad(\mathrm{mm})\end{array}$ & $\begin{array}{l}\text { Peak value of the strain } \\
\qquad(\mu \xi)\end{array}$ \\
\hline \multirow{7}{*}{ A } & L16-1-1 & $3.18(200)$ & 505968 & 10.28 & 1620 \\
\hline & L16-1-2 & $5.06(200)$ & 883159 & 18.25 & \multirow{2}{*}{-} \\
\hline & L16-1-3 & $6.39(200)$ & 1139481 & 29.24 & \\
\hline & L16-2 & $2.25(400)$ & 337214 & 19.46 & 2235 \\
\hline & L16-3-1 & $1.84(600)$ & 297582 & 11.02 & 2004 \\
\hline & L16-3-2 & $2.92(600)$ & 476215 & 20.00 & \multirow{2}{*}{-} \\
\hline & L16-3-3 & $3.69(600)$ & 592120 & 31.54 & \\
\hline \multirow{3}{*}{ B } & L20-1 & $3.18(200)$ & 526625 & 9.51 & 1034 \\
\hline & L20-2 & $2.25(400)$ & 465193 & 16.71 & 1279 \\
\hline & L20-3 & $1.84(600)$ & 327335 & 10.70 & 1146 \\
\hline
\end{tabular}

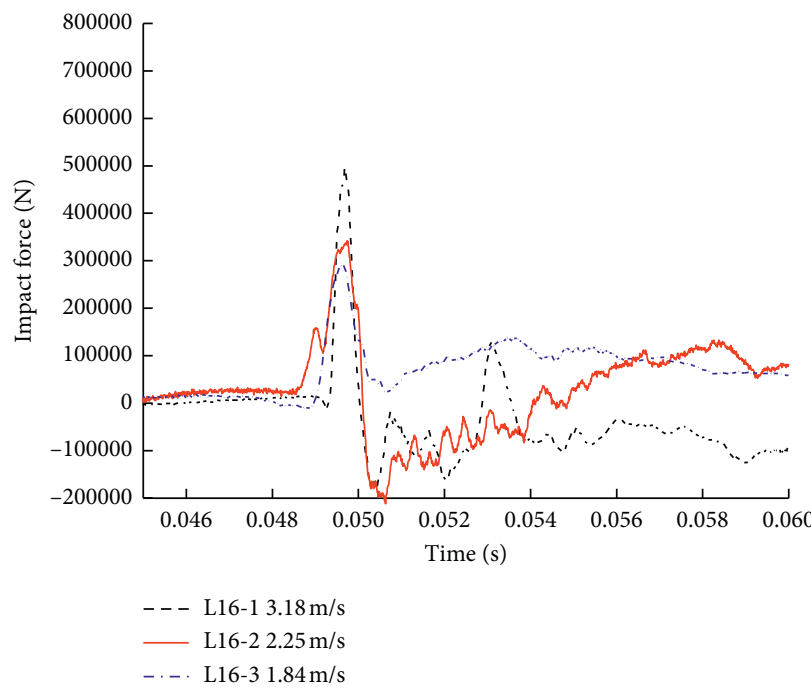

(a)

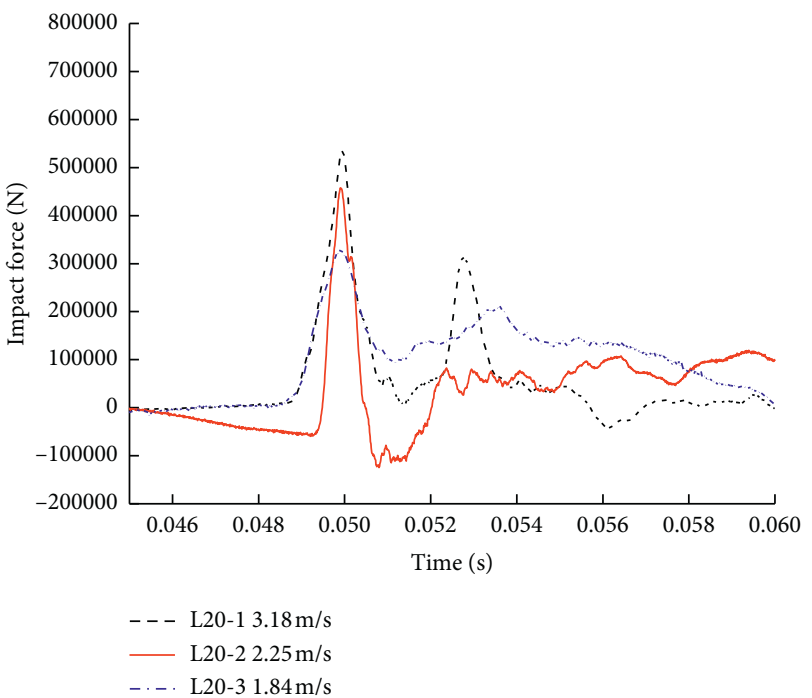

(b)

Figure 3: Time-history curves of the impact force: (a) Group A; (b) Group B.

a main wave peak. Following that, the midspan displacements continued to decline and then rose once again after reaching the minimum value. This had resulted in the formation of a wave trough. When the displacements had risen to a certain value, the displacement curve tended to be horizontal. The displacement time-history curve of some beams shows negative values. The main reason is that the first impact energy in this experiment is relatively small, and the proportion of energy consumed by the elastic deformation of the beam has increased. So, there will be a greater degree of rebound. There were residual displacements which were observed in the midspan due to the plastic damage of the beam during the process of impact. It can be seen when comparing the two images shown in Figure 4 that under the action of equal energy impact loads, the peak displacements of the beam first increased and then decreased with the increase in impact velocity. In addition, with the increases in the reinforcement ratios, the peak displacement of the beam had decreased. The residual displacements of the beam were mainly related to the reinforcement ratios and impact energy. Therefore, it was indicated that the impact velocity and mass had little influence on the residual displacements.
As can be seen in Figure 5, the reinforcement strain increased when the falling hammer collided with the beam and decreased after reaching the peak, forming a main wave peak, and then tended to be horizontal. The duration of the main wave peak was approximately 14 to $28 \mathrm{~ms}$, which was similar to that of the main wave peak of the displacement time-history curve. Therefore, by comparing A and B in Figure 5, it was found that, under the action of equal energy impact loads, the peak strain of the reinforcement first increased and then decreased with the increases in the impact velocity. In addition, with the increases in the reinforcement ratio, the peak strain of the reinforcement had decreased.

As detailed in Figures 3-5, the occurrence of peak values of the displacements and reinforcement strain was delayed relative to the peak values of the impact force. This was due to the fact that the beam was in the local response stage before the development of the midspan displacements. At that stage, the impact force of the falling hammer gradually had transformed into the inertial force of beam itself, and the inertial force had propagated to both ends of the beam in the form of stress waves. Then, when the stress waves reached the bearings and the beam 


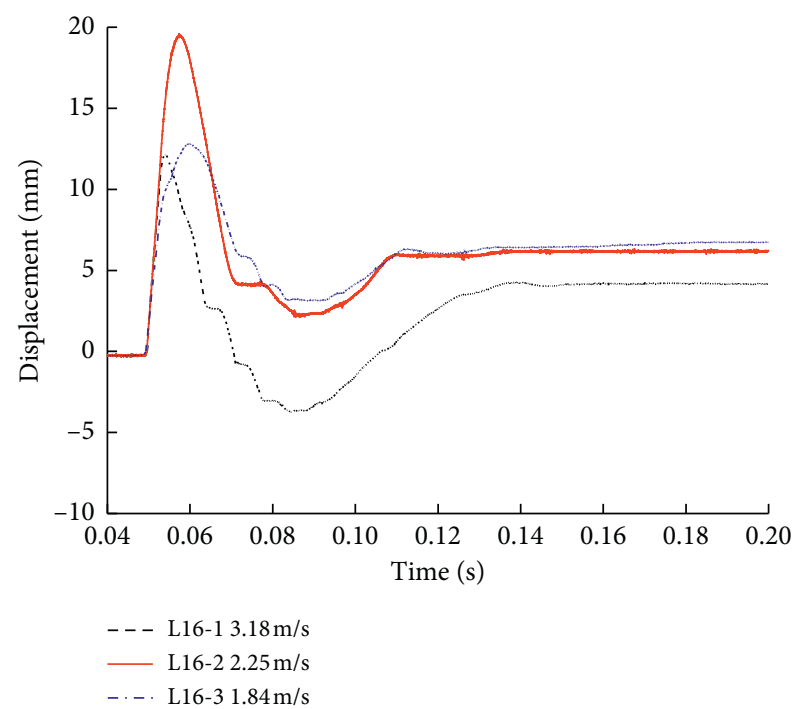

(a)

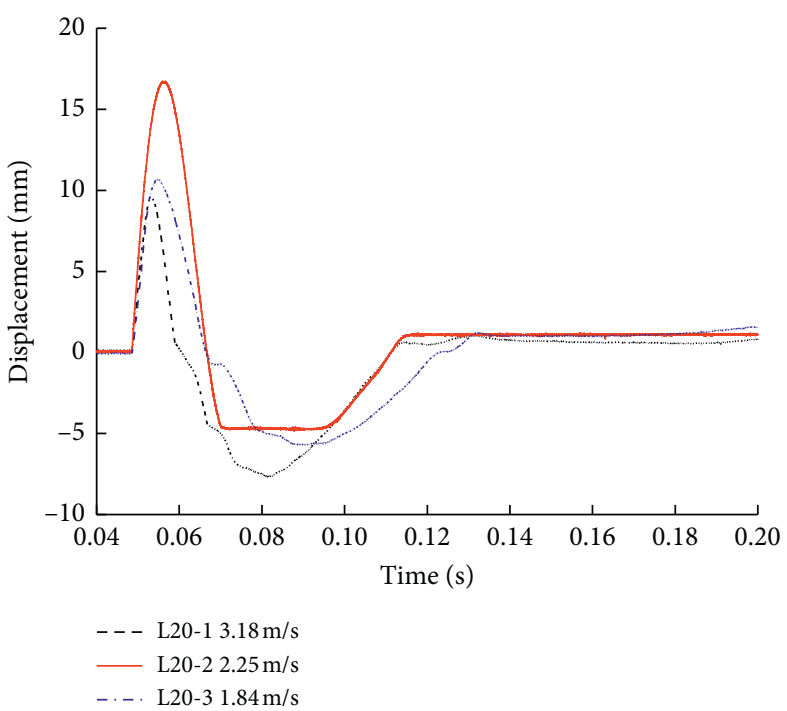

(b)

Figure 4: Time-history curves of the displacements: (a) Group A; (b) Group B.

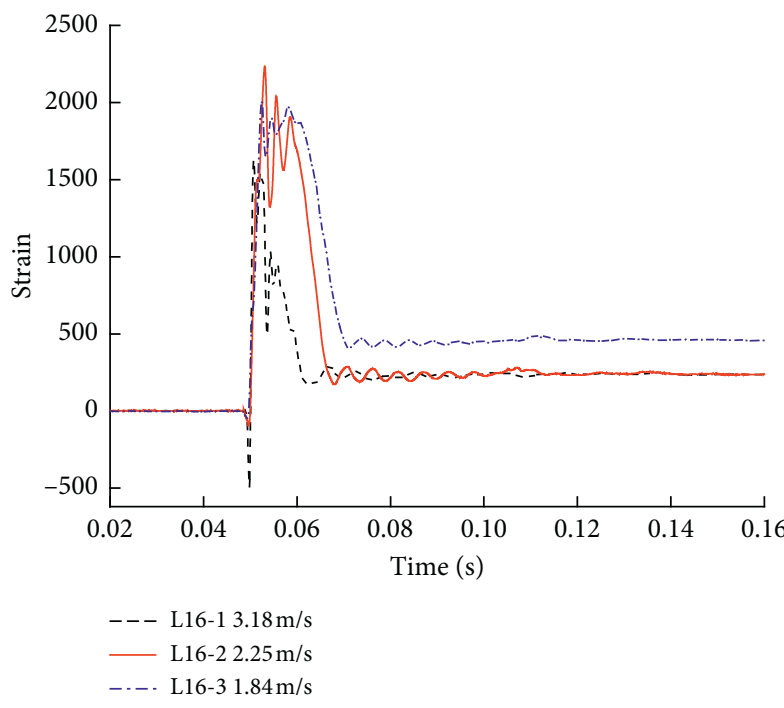

(a)

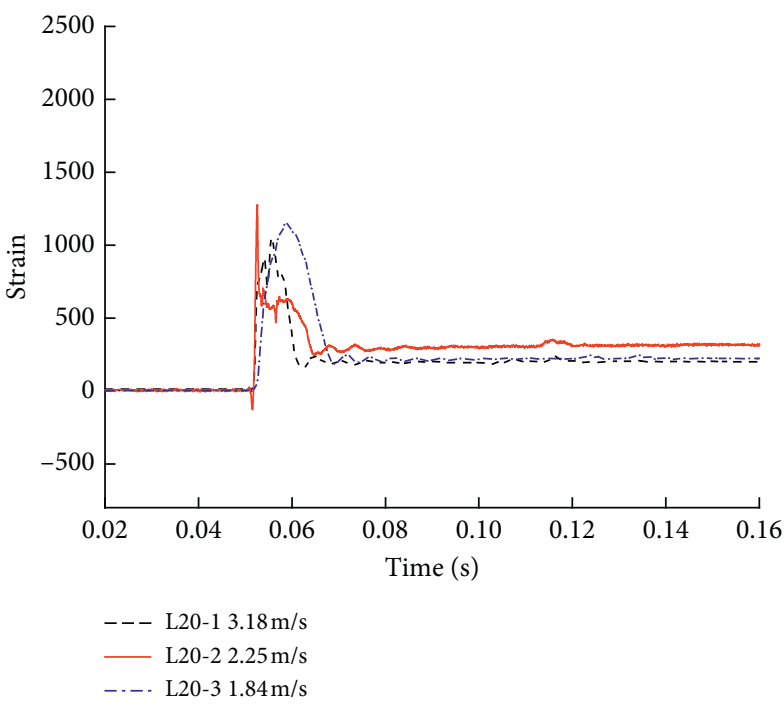

(b)

Figure 5: Time-history curves of the strain: (a) Group A; (b) Group B.

began to respond as a whole. The joint action of the inertial force and the bearing reaction force caused the entire beam to undergo downward accelerated motion. During that process, a small part of the mechanical energy of the falling hammer was used for the impact energy consumption in local areas of the beam-hammer contact. A large portion of the mechanical energy was stored by the beam and consumed by the following three parts: energy consumption by local damages; energy consumption by overall damages; and energy consumption by the deformations of the reinforcements and concrete material. In this study's experimental tests, the midspan displacements and reinforcement strain of the beam were observed to first increase and then decrease with the increases in the impact velocity. These findings indicated that combinations of different velocities and masses had resulted in the greatest damage and failure under the actions of equal energy impact loads.

3.2. Analysis of Cumulative Impact Data. Figure 6 shows the time-history curve of the impact forces of beams L16-1 and L16-3 under the actions of equal energy cumulative impact loads. The difference between the peak impact force of the L16-1-1 and L16-3-1 beams was determined to be 208,386 N. The difference between the peak force of the L16-1-3 and L16-3-3 beams was $547,361 \mathrm{~N}$, which indicated that the 
impact peak value of the beam was greater when the hammer velocity was higher (lower mass) regardless of whether it was a single impact or cumulative impacts. In regard to the cumulative impacts of a single beam, the increase rates of the three impact force peaks of beam L16-1 were 74\% and 51\%, respectively, when the impact velocity increased from $3.18 \mathrm{~m} / \mathrm{s}$ to $6.39 \mathrm{~m} / \mathrm{s}$. In addition, it was observed that when the impact velocity increased from $1.84 \mathrm{~m} / \mathrm{s}$ to $3.69 \mathrm{~m} / \mathrm{s}$, the three impact peak values of beam L16-3 increased by $43 \%$ and $38 \%$, respectively. These results suggested that with the increases in the cumulative impact times, the stiffness damages to the beam gradually increased, and the increase rate of peak value of the impact force became smaller. In addition, the impact speed of beam L16-1 is higher than beam L16-3 each time, so that the increase rate of the corresponding peak impact force is also greater. Therefore, it was concluded that the velocity had greater influences on the peak impact force than the material mass under equal energy cumulative impact load conditions.

Figure 7 shows the displacement time-history curves of the L16-1 and L16-3 beams under the action of equal energy cumulative impact loads. The trends of the displacement time-history curves of each beam subjected to three cumulative impacts were observed to be approximately the same. In regard to the cumulative impact of a single beam, when the impact velocity increased from $3.18 \mathrm{~m} / \mathrm{s}$ to $6.39 \mathrm{~m} /$ $\mathrm{s}$, the increase rate of the three displacement peak values of beam L16-1 was determined to be $78 \%$ and $106 \%$, respectively. In addition, when the impact velocity increased from $1.84 \mathrm{~m} / \mathrm{s}$ to $3.69 \mathrm{~m} / \mathrm{s}$, the increase rates of the three times displacement peak values of beam L16-3 were found to be $81 \%$ and $104 \%$, respectively. These results indicated that with the increases in the cumulative impact times, the stiffness damage of the beam had gradually become aggravated, and the increase rate of midspan peak displacements of the beam was greater. Therefore, the larger the midspan peak displacements were, the greater the residual displacements would be, and the more serious the damage of beams would be. At the same time, through numerical simulation, Wongmatar et al. [24] derived the calculation formula between the maximum displacement $\left(\delta_{\max }\right)$ and the ratio of impact energy $\left(E_{k}\right)$ to static flexural capacity $\left(P_{u}\right)$ : $\delta_{\max }=0.72\left(E_{k} / P_{u}\right)$. Combined with this experiment, when the beam is subjected to cumulative impact load, the $E_{k}$ increases. Due to the damage of the beam in the previous impact, the $P_{u}$ decreases, so the $E_{k} / P_{u}$ increases and the $\delta_{\max }$ increases. Under the same impact way, the impact energy and static bending capacity are the main factors affecting the maximum deflection of the beam. In the present study, the changes in the cumulative impact time-history of the reinforcement strain were found to be similar to those of midspan displacements.

As can be seen in Figures 6 and 7, under the condition of equal energy impact loads, the peak value of the impact force increased with the increases in impact velocity (decreased mass) according to this study's comparison between beams L16-1 and L16-3. However, the displacements had displayed no obvious changes. Therefore, if the local damages were ignored, the damage degrees of the beam could be expressed by the midspan displacements [25], which indicated that it was not accurate to express the impact bearing capacity of a beam by using the impact force. The fact that, under equal energy cumulative impact loads, the relative changes in the displacements of the beam L16-1 and beam L16-3 were observed to be very small, may have indicated that the damage degrees of the beams were mainly related to the impact energy levels.

\section{Numerical Simulations and Verifications}

4.1. Model Establishment and Strain Rate Effect. In order to further study the local failure and overall damage of the beam under equal energy impact load, the finite element software ABAQUS display dynamics module is used to carry out three-dimensional numerical simulation of the experiment. As shown in Figure 8, the drop hammer impact model of the reinforced concrete beam is established. The hammer head is simplified as a cylinder, with a radius of $200 \mathrm{~mm}$; the impact position is in the middle of the span. The mass of the falling weight can be controlled by modifying the material density and model size, wherein it is defined that the falling weight only moves in the vertical direction. Additionally, through a predefined field, the impact velocity of the falling hammer is set. The support is simplified to the rectangular frame structure, shown in Figure 8, to simulate the pressure plate on the upper part of the beam during the test, and is consolidated with the beam. Next, a coupling point is set directly below the support, and through the coupling point, the constraint type of the beam is set to be simply supported. The drop hammer and the support are defined as rigid bodies. The bond slip between rebar and concrete is not considered, and the rebar cage is embedded in the concrete matrix in the form of Embed. The contact between the drop hammer and beam and the beam and support is set as a universal contact. The concrete uses three-dimensional eight-node linear reduction integral solid element C3D8R and introduces element hourglass control. The reinforcement bar adopts the three-dimensional truss element T3D2, and the approximate global size of the mesh is $25 \mathrm{~mm}$.

Due to the complexity of the dynamic responses of reinforced concrete structures under impact load conditions, this study's examination of the concrete material adopted the damage plastic model (CDP) which was proposed by Lubliner et al. [26]. The model parameters are shown in Table 3 . This model has the ability to analyze the mechanical responses of concrete structures under dynamic loading conditions as well as monotonic and cyclic loading conditions. It also considers the differences in the material tension and compression properties. The CDP model is able to describe the irreversible damages to concrete material and can also provide a description of the stiffness degradation behaviors of the material. The characteristic curves of the uniaxial compression and tension of the concrete characterized by decrease in stiffness are detailed in Figure 9. In the present study, the constitutive model of the longitudinal reinforcements and stirrups was the bilinear elastic-plastic model [27]. 


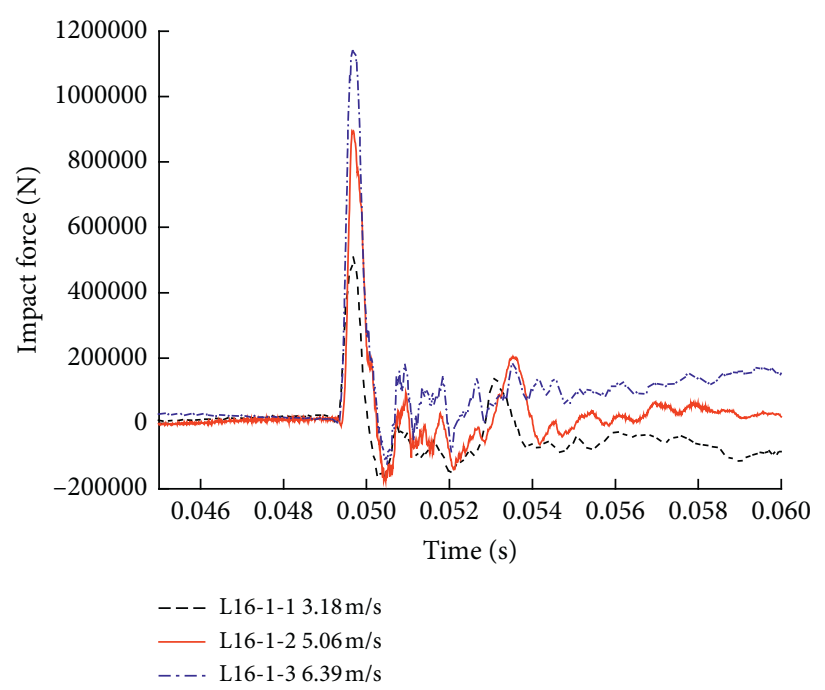

(a)

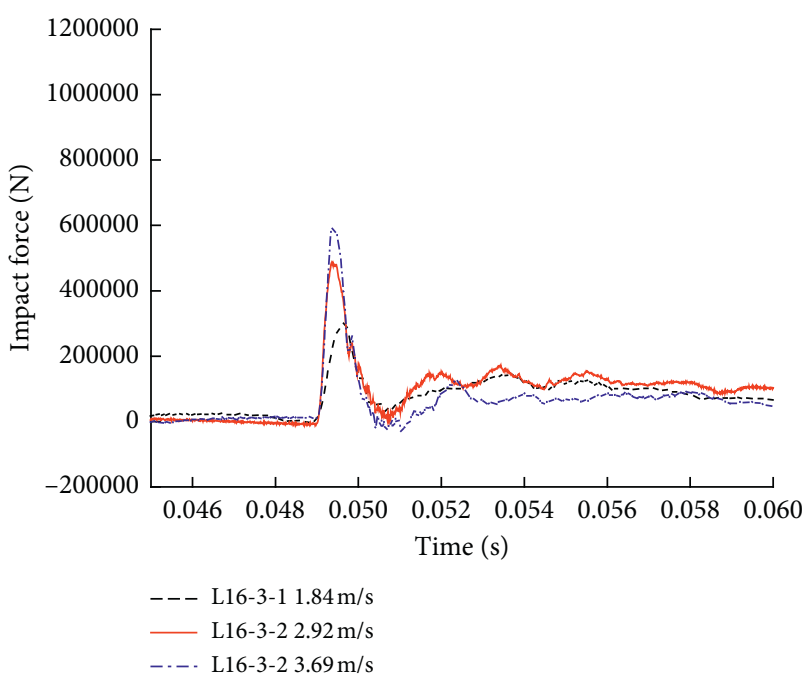

(b)

Figure 6: Time-history curves for the cumulative impact force: (a) L16-1; (b) L16-3.

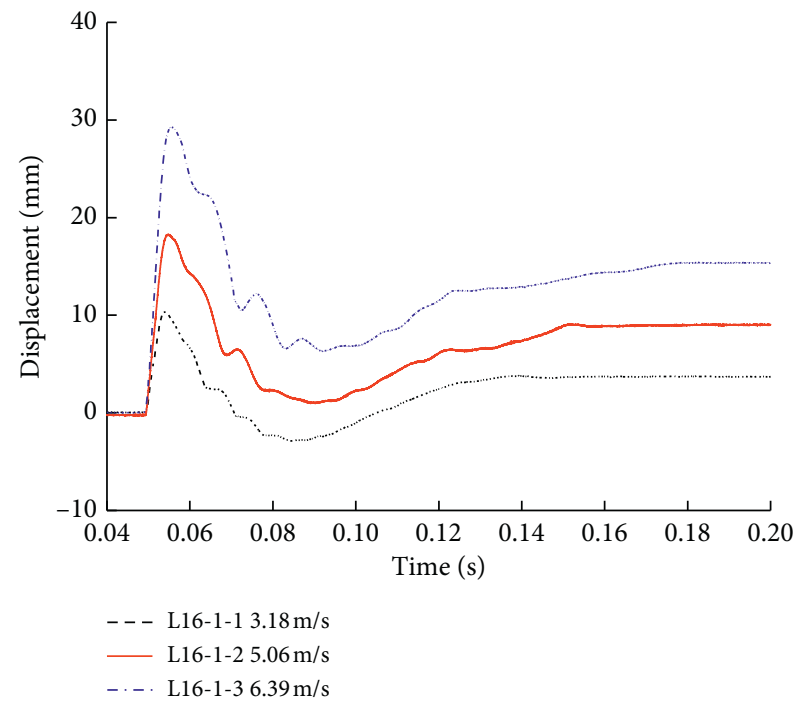

(a)

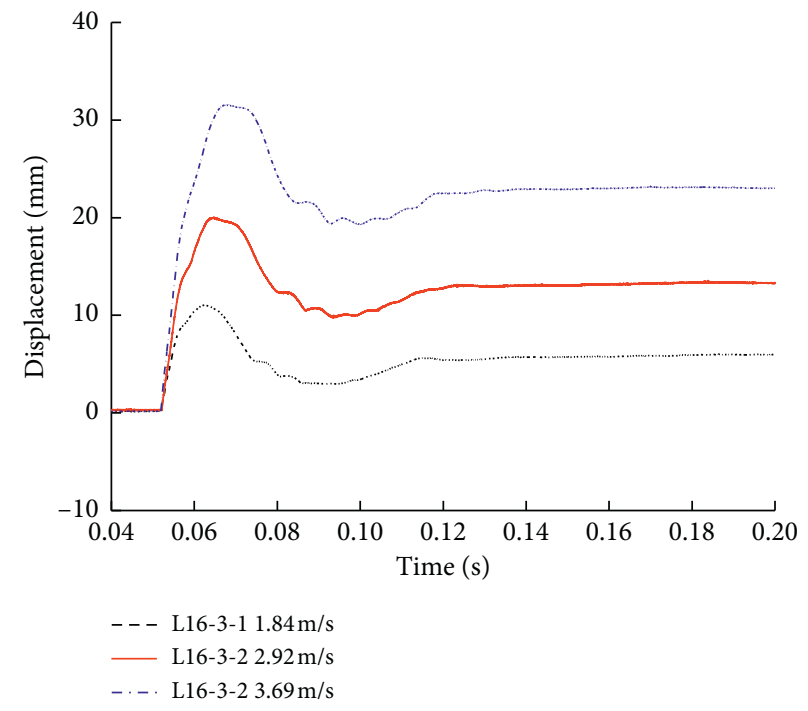

(b)

FIgURE 7: Time-history curves for the displacements after cumulative impacts: (a) L16-1; (b) L16-3.

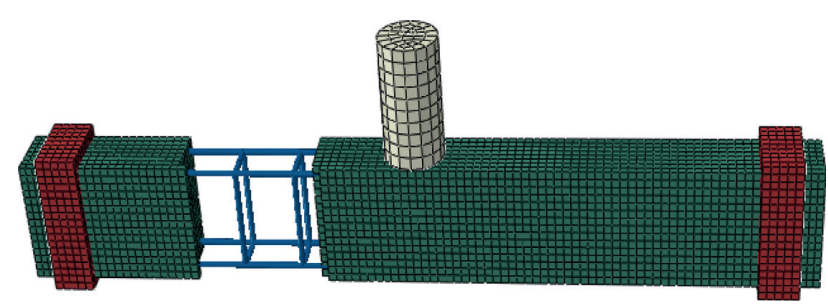

Figure 8: Numerical model diagram.

The strain rate effect is also referred to as the sensitivity rate of the material. Due to the strain rate effects of the materials, the strength of the reinforcements and concrete material tend to increase under dynamic loads. These strain rate effects can be expressed as dynamic amplification factors (DIFs). In this study, the dynamic amplification factors (TDIFs) of the concrete tensile strength, as well as the dynamic amplification factor model (CDIF) of the concrete compressive strength proposed by CEB [28], were used for the numerical simulations as follows:

$$
\mathrm{TDIF}=\frac{f_{\mathrm{ct}, \mathrm{imp}}}{f_{\mathrm{ctm}}}= \begin{cases}\left(\frac{\varepsilon_{\mathrm{ct}}}{\varepsilon_{\mathrm{cto}}}\right)^{0.018}, & \left|\varepsilon_{\mathrm{ct}}\right| \leq 10 \mathrm{~s}^{-1}, \\ 0.0062\left(\frac{\varepsilon_{\mathrm{ct}}}{\varepsilon_{\mathrm{cto}}}\right)^{1 / 3}, & \left|\varepsilon_{\mathrm{ct}}\right|>10 \mathrm{~s}^{-1},\end{cases}
$$


TABLe 3: Parameter table of concrete damage plasticity model.

\begin{tabular}{lccccccc}
\hline Mass density & Young's modulus & Poisson's ratio & Dilatancy angle & Eccentricity & $f_{b 0} / f_{c 0}$ & $k$ & Viscosity parameter \\
\hline $2450 \mathrm{~kg} / \mathrm{m}^{3}$ & $3.25 \times 10^{4} \mathrm{MPa}$ & 0.2 & $35^{\circ}$ & 0.1 & 1.16 & 0.6667 & 0.0005 \\
\hline
\end{tabular}

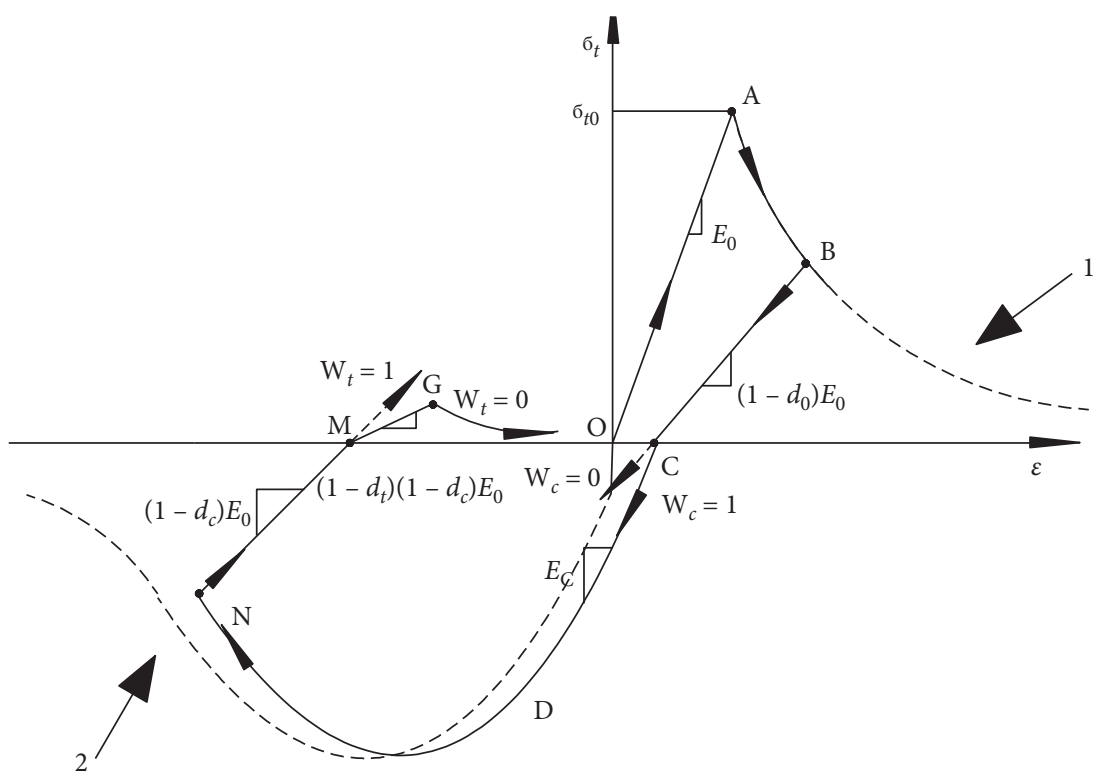

Figure 9: Concrete uniaxial tension and compression characteristic curves.

where $f_{\text {ct,imp }}$ is the tensile strength of the concrete under dynamic loading; $f_{\mathrm{ctm}}$ indicates the tensile strength of the concrete under static loading; $\varepsilon_{\mathrm{ct}}$ denotes the material strain rate; and $\varepsilon_{\text {cto }}$ is the strain rate value under static loading conditions. The scope of the application was $10^{-6} \sim 300 \mathrm{~s}^{-1}$ :

$$
\mathrm{CDIF}=\frac{f_{c, \mathrm{imp}}}{f_{\mathrm{cm}}}= \begin{cases}\left(\frac{\varepsilon_{c}}{\varepsilon_{\mathrm{co}}}\right)^{0.014}, & \left|\varepsilon_{c}\right| \leq 30 \mathrm{~s}^{-1}, \\ 0.012\left(\frac{\varepsilon_{c}}{\varepsilon_{\mathrm{co}}}\right)^{1 / 3}, & \left|\varepsilon_{c}\right|>30 \mathrm{~s}^{-1},\end{cases}
$$

where $f_{c, \text { imp }}$ is the compressive strength of the concrete under dynamic loading conditions; $f_{\mathrm{cm}}$ indicates the compressive strength of the concrete under static loading conditions; $\varepsilon_{c}$ refers to the material strain rate; and $\varepsilon_{\mathrm{co}}$ is the strain rate value under static loading conditions. The scope of the application was $-30 \times 10^{-6} \sim 300 \mathrm{~s}^{-1}$.

The Cowper-Symond model [29] was introduced in this study to represent the strain rate effects of the reinforcements, and its expression was $f_{y}^{\bullet} / f_{y}=1+\left(\varepsilon^{\bullet} / D\right)^{1 / P}$. It was assumed that the model did not change with the strain strengthening effects. The values of $D$ and $P$ were related to the ultimate strengths of the reinforcements, which were taken as 40 and 5, respectively, in this study.

4.2. Model Validation. The validity of this study's model was verified by comparing the damages, impact force, and displacement results among the numerical simulations and test results.

It can be seen in Figure 10 that part of the concrete in the local range of the contact area between the L16-1 concrete beam and the hammer head was crushed, and the cracking in the concrete at the middle and lower parts of the span was mainly formed into three oblique cracks with angles of $45^{\circ}$, as well as a small number of vertical cracks. In beam L16-3, mainly oblique cracks from midspan to support and vertical cracks in the midspan had formed (Figure 11). The crushing of the concrete in the local range of the midspan of the L16-3 beam was observed to be smaller than that of the L16-1 beam, and the midspan displacements of the two beams were similar. The inclination angles of the oblique cracks which had formed in the midspan and the beam ends were the largest. The inclination angles were observed to gradually increase from the bottom to the top and tended to the horizontal in the midspan area. The numerical simulation results are similar to the experimental results.

The impact force time-history curves and midspan displacement time-history curves of numerical simulation and test results for the L16-3 beam are presented in Figures 12 and 13, respectively. It was concluded that the impact force time-history curves trends were observed to be similar. In addition, the peak values of the impact force and displacements were similar, with errors no greater than $10 \%$. This study's numerical model was able to accurately reflect the impact responses of the beams. Figure 14 shows the kinetic energy, internal energy, and hourglass energy curves obtained by the numerical simulation of beam L16-1. The 


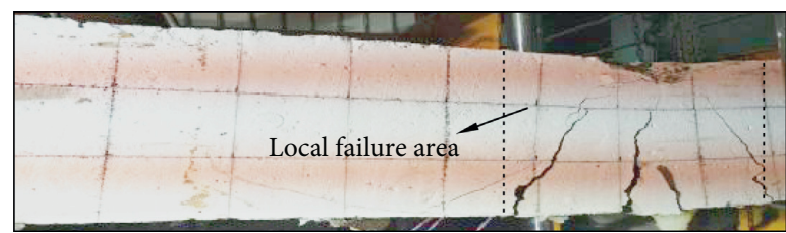

(a)

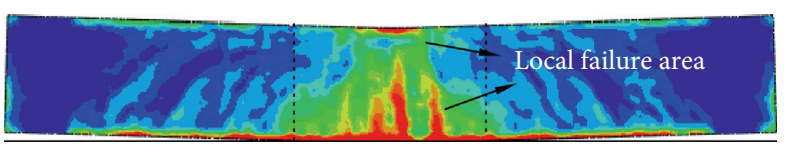

(b)

Figure 10: Beam L16-1.

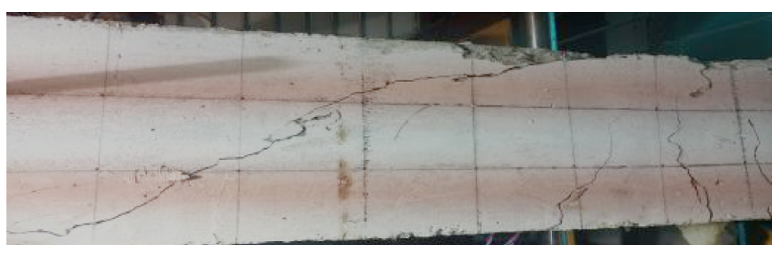

(a)

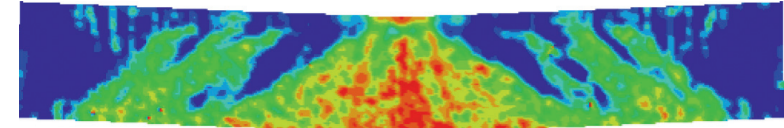

(b)

Figure 11: Beam L16-3.

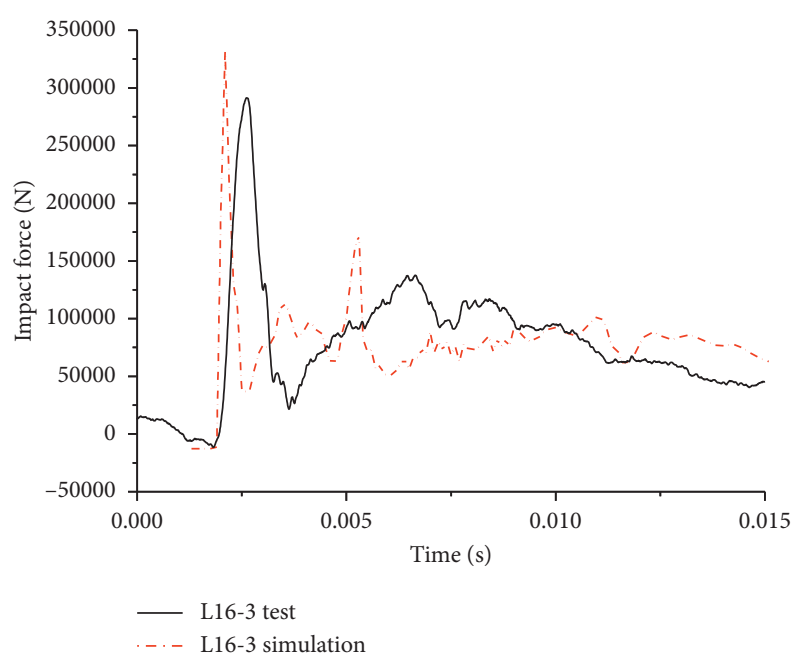

FIgURE 12: Time-history curves of the impact force.

ratio of hourglass energy to kinetic energy is within $10 \%$, which shows that the mesh convergence result is better. As a result, the impact resistance of the beams and the influence of the different control variables on the mechanical behaviors of the beams under impact load conditions could be effectively analyzed.

\section{Analysis of the Local and Overall Damages}

The damages in the beam-hammer contact areas and punching failure areas of the beam midspans were defined as local damages, and the approximate range is shown in Figure 10. The scope, type, and degrees of the local damages were all determined to affect the overall damages of the beams. In the research investigation, the development of local damages to the beams under equal energy impact loads and the local damages influencing effects on the overall

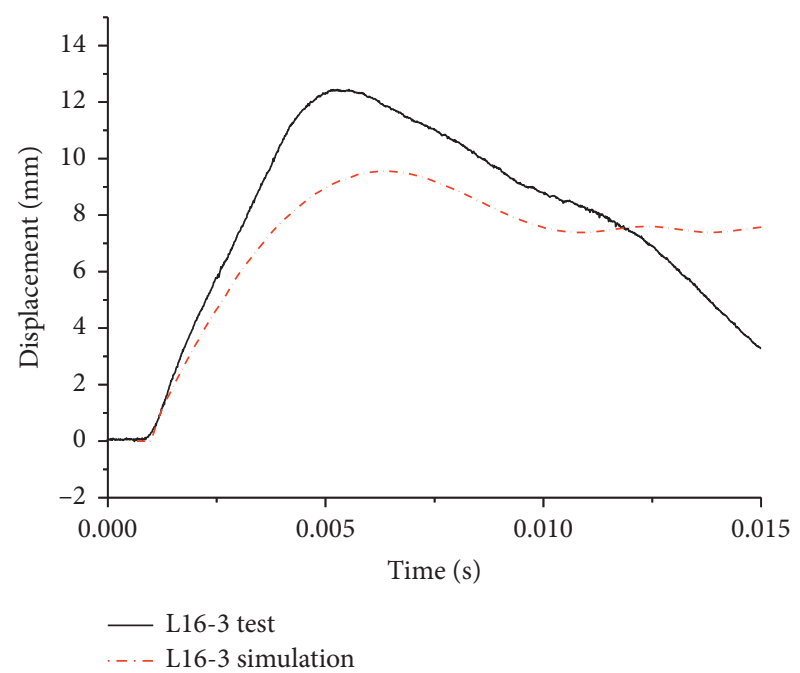

Figure 13: Time-history curves of the displacements.

damages to the beams were determined by using a finite element method.

5.1. Analysis of Local Damages. Figure 15 shows the development process of the local damages of the L16-2 beam. It could be seen in the figure that, starting from the impact acting point, the stress had diffused downward and toward both ends of the beam. Then, with the development of the time history, the stress was mainly diffused at an oblique angle of $45^{\circ}$ in the local range before it was transmitted to the bearings. Next, at the end of the local responses, the stress had propagated from the beam-hammer contact area to the beam end bearings. Figures 16 and 17 show the compressive damages and tensile damages of the beam at the end of the peak impact force, respectively. At that time, the stress waves had not yet been transmitted to the bearings, and the beam 


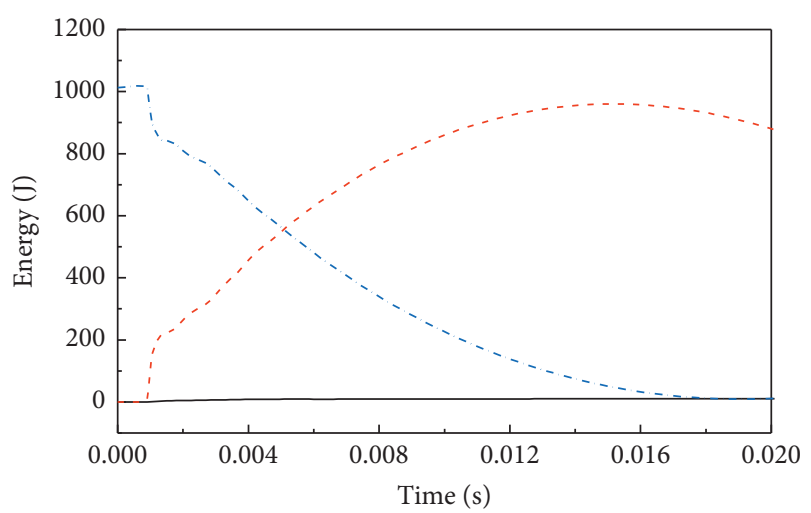

- Hourglass energy
- - - Internal energy
- - - Kinetic energy

Figure 14: Energy time-history curve.

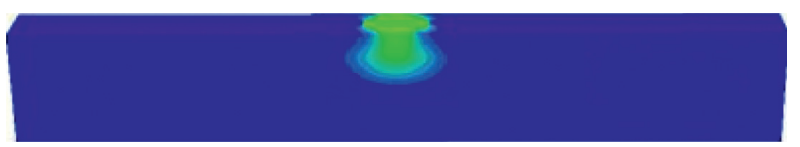

(a)

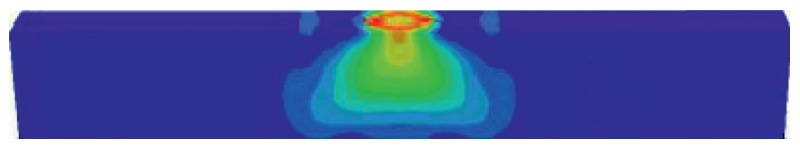

(b)

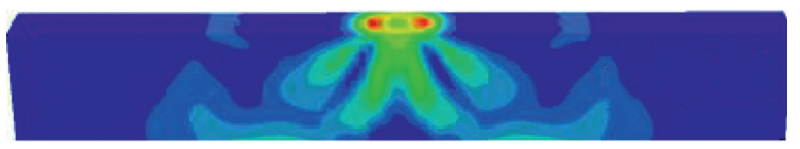

(c)

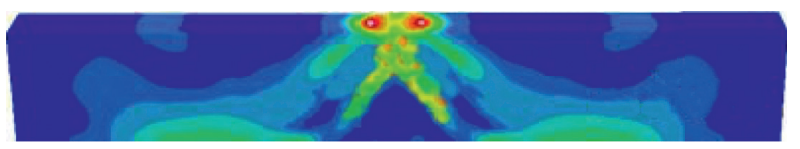

(d)

Figure 15: Development of the local damages: (a) $1 \mathrm{~ms}$, (b) $1.2 \mathrm{~ms}$, (c) $1.4 \mathrm{~ms}$, (d) $1.7 \mathrm{~ms}$.

was in a local response stage. It can also be seen in the figures that, under the equal energy impact loads, the scope and degrees of the local damages to the beam had increased with the increases in impact velocity, and the local damages to the beam decreased with increases in the reinforcement ratios. Therefore, combined with the test results displayed in Figures 10 and 11, it was clear that the oblique angles of the local cracks decreased with the decreases in impact velocity, and the cracks tended to be vertical cracks. Therefore, the local damages to the beams clearly varied with the changes in the impact loads and reinforcement ratios and affected the overall damage of the beam.

5.2. Analysis of the Overall Damages. The failure modes and crack development of beams under impact loads are generally very different from those under static loads. Due to the

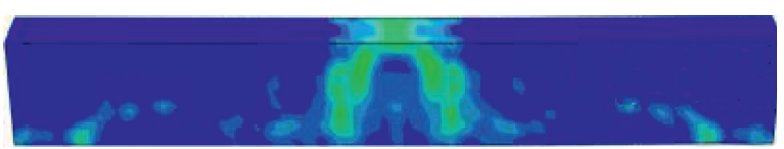

(a)

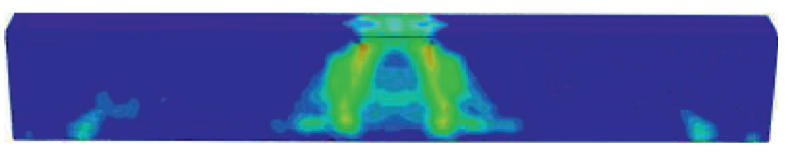

(b)

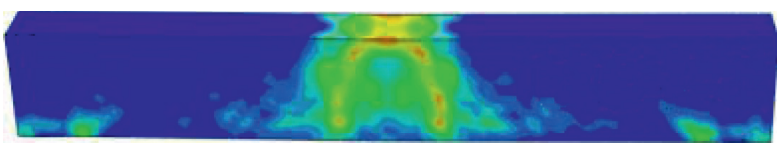

(c)

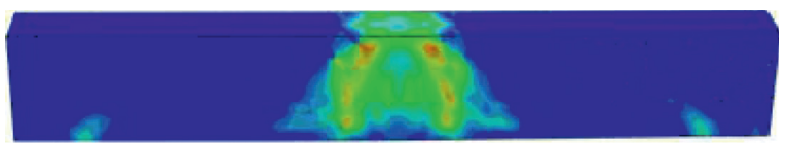

(d)

FIgURE 16: Local compressive damages: (a) L16-3-C, (b) L16-2-C, (c) L16-1-C, (d) L20-1-C.

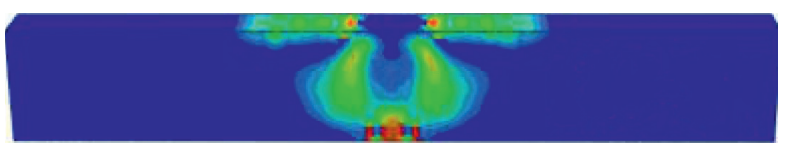

(a)

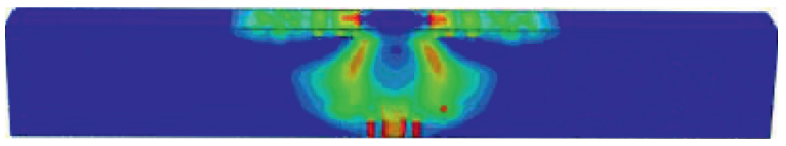

(b)

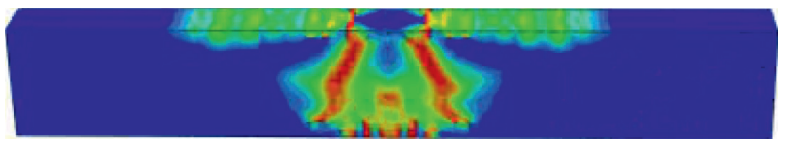

(c)

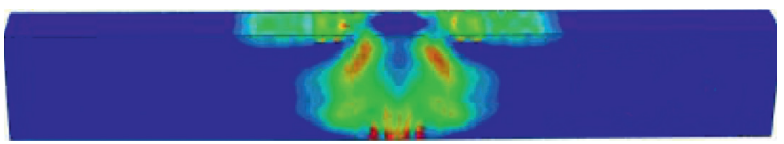

(d)

Figure 17: Local tensile damages: (a) L16-3-T, (b) L16-2-T, (c) L16-1-T, (d) L20-1-T.

joint influence of four types of effects, beams subjected to bending failures under static loads may also experience shear failures under impact loads. As detailed in Figure 18, the beam-hammer impacts were divided into a local response stage and an overall response stage. During the local response stage, the beam was impacted by the hammer, and the first impact damages occurred at the contact position. The beam-hammer contact location was covered by the concrete of the compression area, and the damages to concrete in the compression area led to decreases in the bending resistance of the beam, thereby influencing the 


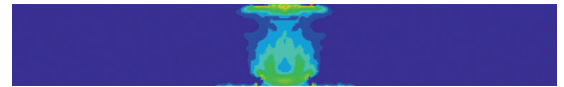

(a)

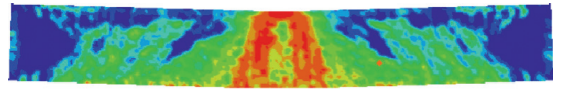

(d)

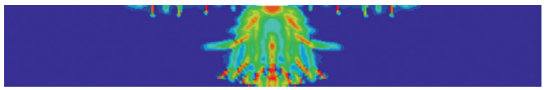

(b)

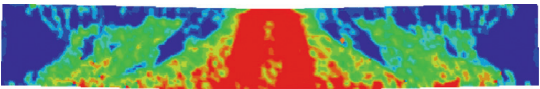

(e)

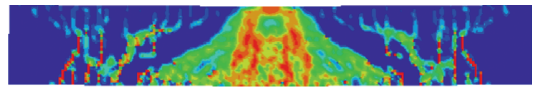

(c)

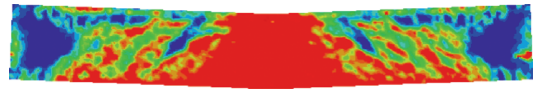

(f)

FiguRE 18: Crack development diagram of the L16-2 beam: (a) $1 \mathrm{~ms}$, (b) $1.5 \mathrm{~ms}$, (c) $5 \mathrm{~ms}$, (d) $8 \mathrm{~ms}$, (e) $10 \mathrm{~ms}$, (f) $15 \mathrm{~ms}$.

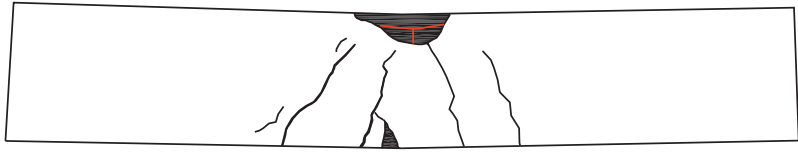

(a)

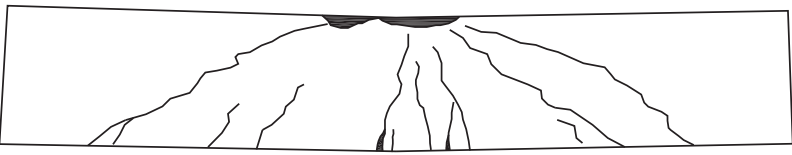

(c)

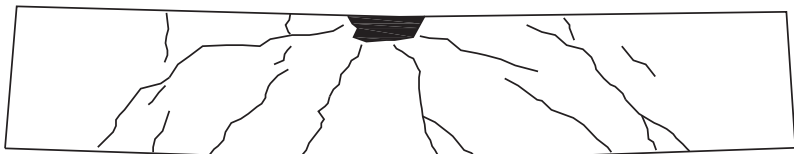

(e)

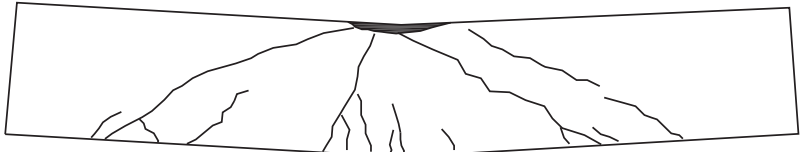

(b)

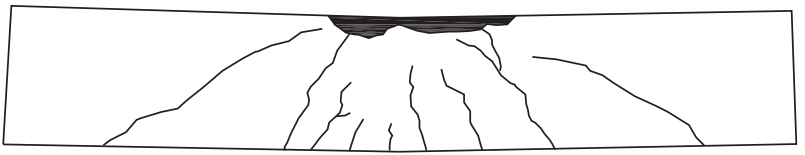

(d)

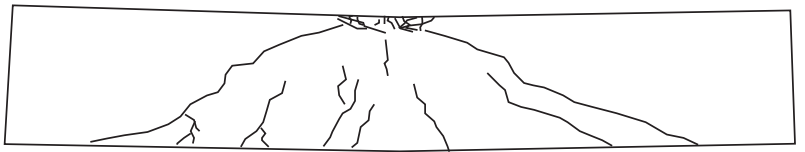

(f)

FIGURE 19: Schematic diagram of the beam damages: (a) L16-1, (b) L16-2, (c) L16-3, (d) L20-1, (e) L20-2, (f) L20-3.

failure mode of the beam. Then, the stress waves had propagated downward and toward the left and right ends of the beam. However, prior to the stress waves reaching the bearings, the connection part between the bearings and the beam had not yet been affected by the impact load and could be regarded as a fixed hinge support area. As a result, the load-bearing span of the beam was reduced and concentrated in the local midspan areas. The bending strength of the beam in the midspan areas then increased with the decreases in the load-bearing span. Therefore, it could be discerned that the beams under impact loads had mainly formed oblique cracks due to shear failures in the midspan areas, which appeared to be A-shaped in the local range. This was considered to be a unique shear effect of the beam under the impact loading conditions and had mainly occurred during the local response stage. When the stress waves were transmitted to the bearings, the beam began to move in a downward direction as a whole under the joint actions of inertia force and bearing reaction force. This was the key to determining the overall failure mode of the beam. It was found in this study that, if the resultant force of the combined inertia force and bearing reaction force was greater than the bending capacity of the entire beam, then bending failure would occur. Otherwise, shear failure would occur. However, if the resultant force was greater than both the bending resistance and shearing resistance of the beam, then bending shear failure would occur. Therefore, in this study, it was concluded that the local punching shear failure had not accurately represented the failure types of the entire beam.
Figure 19 shows a schematic diagram for the beam damages under equal energy impact loads. It can be seen in the figure that the impact velocity of the L16-1 beam was high, the local damages were relatively large, and no obvious cracks were observed in other parts of the beam. A large part of the mechanical energy of the falling hammer had been converted into energy consumed by actions of the local failure. This had resulted in that fact that the resultant force of the combined inertial force and bearing reaction force during the overall response stage was less than that of the bending and shearing resistance capacity of the entire beam. Then, it was found that, with the decreases in impact velocity, the beam tended toward static load conditions, and the local damages in the midspan areas were noticeably smaller. In addition, more energy acted on the overall response stage of the beam. The inertial force effects played a major role during the overall response stage, part of which caused the beam to produce a downward acceleration. Also, the other part was used to generate the supporting force. The curve distribution of the inertial force had reduced the bending moment in the midspan of the beam, which caused the beam to be more prone to shear failure. However, it was observed that with the decreases in impact velocity, the effects of the inertial force were weakened and the beam was closer to the failure type of static loading. Therefore, it was indicated in this study that with the decreases in impact velocity, the extent and scope of local failures had decreased; the inclined angles of the inclined cracks in the midspan had also decreased; finally, the load on the beam tended to be 
static load, and the bending moment in the midspan of the beam increased. The Group A beam mainly experienced bending failure under static loading conditions. With the decrease of impact velocity, the widths of the inclined cracks from the beam's midspan areas to the bearings decreased gradually from the L16-2 beam to the L16-3 beam. In addition, the bending cracks gradually increased in the midspan areas, and the failure mode of beam tended to be the bending failure of static load. In the same way, the Group B beams mainly underwent shear failure under static loading, and the inclination angles of the inclined cracks in the midspan areas were observed to gradually decrease due to the weakening of the local failures with the decreases in impact velocity. However, the inclined cracks from the beam's midspan areas to the bearings were found to gradually widen, and the beam tended to display a shear failure mode.

\section{Conclusions}

In this paper, the mechanical behaviors of $\mathrm{RC}$ beams under equal energy impact loading conditions were examined by using both experimental tests and numerical simulations. The impact force, displacement, strain, and damage values obtained from this study's tests were analyzed in order to obtain the following conclusions:

(1) Under the action of equal energy impact loads, the peak values of the impact force of the beams were found to increase with the increases of impact velocity. In addition, the impact velocity and stiffness levels of the beams had increased the size and frequency of subsequent peak values of the beams. The displacement and reinforcement strain of the beams first increased and then decreased with the increases of impact velocity. When the impact velocity is $2.25 \mathrm{~m} / \mathrm{s}$ and the impact mass is $400 \mathrm{~kg}$, the beam has the most serious damage.

(2) It was found that, with the cumulative impact, the stiffness of the beam decreased and the displacement increase rates of the L16-1 beam during the last two impacts were $78 \%$ and $106 \%$, respectively. Furthermore, the initial impact displacement peak value and cumulative impact displacement peak value increase rates of beam L16-3 and beam L16-1 were similar. The increase rates of the impact force peak values of the L16- 1 beam during the last two impacts were $74 \%$ and $51 \%$ and those of the $L 16-3$ beam were $43 \%$ and $38 \%$, respectively. The stiffness losses of the beams aggravated the development of cumulative impact displacements and reduced the increase rates of the impact force.

(3) According to the experimental results and tensile and compression damage obtained from the numerical simulation results, it can be concluded that, under the same energy impact load, as the impact velocity increases, the local damage of the beam increases. This is mainly reflected in the scope and extent of local damage and the development of diagonal cracks. Additionally, as the impact mass increases, a greater amount of energy acts on the overall response stage of the beam, and the overall damage becomes more severe. Furthermore, the failure mode of the beam L16 has also changed, so that when the impact velocity is $1.84 \mathrm{~m} / \mathrm{s}$, the beam mainly undergoes bending failure. Secondly, when the impact velocity is $2.25 \mathrm{~m} / \mathrm{s}$, the beam undergoes bending and shear failure; eventually, when the impact velocity is $3.18 \mathrm{~m} / \mathrm{s}$, the beam mainly undergoes partial punching and shear failure. The damage development of beam L20 is similar to that of beam L16.

In summary, in this study, the influence of different loading types (including single loading and cumulative loading and different combinations of impact velocity and mass) on the damage degree and failure mode of reinforced concrete beams under the same total impact energy is studied by experiments and finite element simulation. This provides a reference for the damage assessment of the specimen after having been subjected to the same energy and different impact methods. The specimens that are susceptible to high-speed impact loads, which should strengthen the anti-impact protection at the point of impact, and the specimens, which are susceptible to low-speed impact loads, should be designed to strengthen the overall shear resistance.

\section{Discussion}

In this study, experimental testing was carried out under low-velocity impact conditions. It was observed that, within a certain range, the range of the local punching shear of the beams increased with the increases in the impact velocity. This was considered to be related to the internal bonds of concrete beams. However, at higher impact velocities, the changes in the local damage ranges of the beam require further study. The impact force values can reflect the impact resistance of a beam to a certain extent. However, during the examination of impact force in this study, the expressions of the impact resistance capacities of the beam were not found to be accurate. Consequently, it was recommended that the expressions of the impact bearing capacities of the beams be further investigated in future research studies.

\section{Data Availability}

The test data are included within the article and can be made freely available.

\section{Conflicts of Interest}

The authors declare that they have no conflicts of interest.

\section{Acknowledgments}

The research findings described in this paper were sponsored by the Major Project (Natural Science) of the Department of 
Education of Guangdong Province (2014KZDXM064), the Science and Technology Innovation Project of Department of Education of Guangdong Province (2013KJCX0188), and the Civil Engineering Technology Research Center of Guangdong Province.

\section{References}

[1] C. Zhang, G. Gholipour, and A. A. Mousavi, "Blast loads induced responses of RC structural members: state-of-the-art review," Composites Part B: Engineering, vol. 195, Article ID 108066, 2020.

[2] Y. B. Guo, G. F. Gao, L. Jing, and V. P. W. Shim, "Quasi-static and dynamic splitting of high-strength concretes-tensile stress-strain response and effects of strain rate," International Journal of Impact Engineering, vol. 125, pp. 188-211, 2019.

[3] X. Guo, Stress Wave Propagation in Concrete Structure under Impact Loading, National University of Defense Science and Technology, Changsha, China, 2010.

[4] S. Saatci and F. Vecchio, "Effects of shear mechanisms on impact behavior of reinforced concrete beams," ACI Structural Journal, vol. 106, no. 1, pp. 78-86, 2009.

[5] F. Liu, Q. Luo, B. Yan et al., "Numerical study on the failure mode of RC column subjected to lateral impact," Vibration and Shock, vol. 36, no. 16, pp. 122-127, 2017.

[6] M. Li, Effects of Rate-dependent Properties of Material on Dynamic Properties on Reinforced Concrete Structural, Dalian University of Technology, Dalian, China, 2011.

[7] X. Zhou, R. Zhang, R. Xiong, G. Zhang, and X. Wang, "An experimental study of the impact mechanical properties of RC beams following replacements of stainless steel reinforcements of equal strength," Advances in Materials Science and Engineering, vol. 2019, Article ID 3635974, 16 pages, 2019.

[8] G. Gholipour, C. Zhang, and A. A. Mousavi, "Loading rate effects on the responses of simply supported RC beams subjected to the combination of impact and blast loads," Engineering Structures, vol. 201, Article ID 109837, 2019.

[9] Y. Fang, J. Qu, and F. Xiang, "Experimental and numerical simulation of beam members under low velocity impact load," Heilongjiang Science and Technology Information, vol. 25, no. 13, pp. 116-117, 2015.

[10] N. Kishi, H. Mikami, and T. Ando, "Impact-rsistint behaviour of shear-failure-type RC beams under falling-weight impact loading," in Proceedings of the 7th International Conference on Structures under Shock and Impact, pp. 499-508, Montreal, Canada, 2002.

[11] J. Ozbolt and A. Sharma, "Numerical simulation of reinforced concrete beams with different shear reinforcements under dynamic impact loads," International Journal of Impact Engineering, vol. 38, no. 12, pp. 940-950, 2011.

[12] V. Dey, A. Bonakdar, and B. Mobasher, "Low-velocity flexural impact response of fiber-reinforced aerated concrete," Cement and Concrete Composites, vol. 49, no. 1, pp. 100-110, 2014.

[13] X. Zhou, R. Zhang, G. Zhang, and X. Wang, "Experimental study on impact mechanical properties of RC beams replaced by stainless steel bars with constant cross section," Journal of Xinyang Normal University, vol. 32, no. 3, pp. 487-491, 2019.

[14] C. Zhang, G. Gholipour, and A. A. Mousavi, "Nonlinear dynamic behavior of simply-supported RC beams subjected to combined impact-blast loading," Engineering Structures, vol. 181, pp. 124-142, 2019.

[15] G. Dou, X. Du, and L. Liang, "Experimental study on the behavior of high strength reinforced concrete beams under impact load," Journal of Tianjin University, vol. 47, no. 12, pp. 1072-1080, 2014.

[16] L. Jin, J. Xu, R. Zhang, and X. Du, "Numerical study on the impact performances of reinforced concrete beams: a mesoscopic simulation method," Engineering Failure Analysis, vol. 80, pp. 141-163, 2017.

[17] D. Zhao and W. Yi, "Anti-impact behavior and design method for RC beams," Vibration and Impact, vol. 34, no. 11, pp. 139-145, 2015.

[18] W. Zhao and Q. Jiang, "Study on local response characteristics of RC beams under impact loading," Journal of Hunan University, vol. 46, no. 3, pp. 25-32, 2019.

[19] K. Fujikake, T. Senga, N. Ueda, T. Ohno, and M. Katagiri, "Study on impact response of reactive powder concrete beam and its analytical model," Journal of Advanced Concrete Technology, vol. 4, no. 1, pp. 99-108, 2006.

[20] A. Q. Bhatti, N. Kishi, H. Mikami, and T. Ando, "Elastoplastic impact response analysis of shear-failure-type RC beams with shear rebars," Materials \& Design, vol. 30, no. 3, pp. 502-510, 2009.

[21] L. Jin, R. Zhang, G. Dou, J. Xu, and X. Du, "Experimental and numerical study of reinforced concrete beams with steel fibers subjected to impact loading," International Journal of Damage Mechanics, vol. 27, no. 7, pp. 1058-1083, 2018.

[22] R. Zhang, J. Liu, X. Du, and G. Dou, "Mechanical behavior of SFRC beams subjected to both impact and fire loadings," Explosion and Shock, vol. 39, no. 9, pp. 63-75, 2019.

[23] G. Woisin, "Design against collision," Schiff \& Hafen, vol. 31, no. 2, pp. 1059-1069, 1979.

[24] P. Wongmatar, C. Hansapinyo, V. Vimonsatit, and W. Chen, "Recommendations for designing reinforced concrete beams against low velocity impact loads," International Journal of Structural Stability and Dynamics, vol. 18, no. 9, p. 1850104, 2018.

[25] S. Tachibana, H. Masuya, and S. Nakamura, "Performance based design of reinforced concrete beams under impact," Natural Hazards and Earth System Sciences, vol. 10, no. 6, pp. 1069-1078, 2010.

[26] J. Lubliner, J. Oliver, S. Oller, and E. Oñate, "A plastic-damage model for concrete," International Journal of Solids and Structures, vol. 25, no. 3, pp. 299-326, 1989.

[27] T. B. Zhan, Study on Mechanical Behavior of Reinforced Concrete Beams under Static and Dynamic Loads, Beijing University of Technology, Beijing, China, 2016.

[28] Euro-Intemational Committee for Concrete, CEB-fip model code 2010, Fib Bulletin, Euro-Intemational Committee, Lausanne, Switzerland, 2010.

[29] N. Jones, Structural Impact, Cambridge University Press, Cambridge, UK, 2011. 